\title{
3 Dancing with the Virus: Moving through the Streets
}

Use value, long expelled from the field of the economics, is back, and the useful is now king. Money cannot buy the vaccine that we don't have, cannot buy the protective masks that have not been produced, cannot buy the intensive care departments that have been destroyed by the neoliberal reform of Europe's healthcare system. No, money cannot buy what does not exist. Only knowledge, only intelligent labor can buy what does not exist. ${ }^{95}$

\begin{abstract}
A few months before my friend died from cancer, she said that she wasn't fighting anything. She just took the drugs and underwent strange-sounding treatments, like getting her brain "zapped." Or at least, she went for any treatment she was offered while she wasn't considered too statistically close to death for the treatment costs to potentially "pay off." In the meantime, her thirty-seven year-old body withered, one damaged cell at a time. Anne Boyer speaks to the complexities of the gendered politics of cancer when she writes that "the work of care and the work of data exist in a kind of paradoxical simultaneity: what both hold in common is that they are done so often by women, and like all that has historically been identified as women's work, it is work that can go by unnoticed. It is often noted only when absent." as COVID-19, intersections between care, data, and death become visible in new ways that affect larger institutional and social structures - and indeed, these intersections become particularly visible when absent because they are damaged, abused, repressed, or left uncared for. (HS)
\end{abstract}

On February 29, 2020, only twelve days before the country was locked down, the National Gallery of Denmark opened an exhibition of the installation Circuits (Interpassivities) $^{97}$ by Danish artist Jesper Just. As one walks into the room, a video displays a group of immobilized dancers to whom patches are attached. The patches send electronic stimuli into the dancers' bodies, making their limbs jerk and their bodies contract at intervals apparently determined by the musical score. The electronic impulses that normally take place inside a dancer's body when they respond to music, turning sound vibrations into movements, here become externalized, become physical touches, turned inside out, and made available for scrutiny as a process of mechanical jerks bereft of human volition. The patches placed on the dancers' skin are the kind normally used in physiotherapy to train the muscles for rehabilitation after injury. They mimic the way the brain sends electronic impulses that make your muscles do what you want them to do. In this way, the dancers' bodies - bodies that epitomize control and motor coordination, and which we are predisposed to see as moving to the music - are literally moved by the music as electronic impulses. Circuits between bodies and technologies are thus reconfigured, raising questions about who 


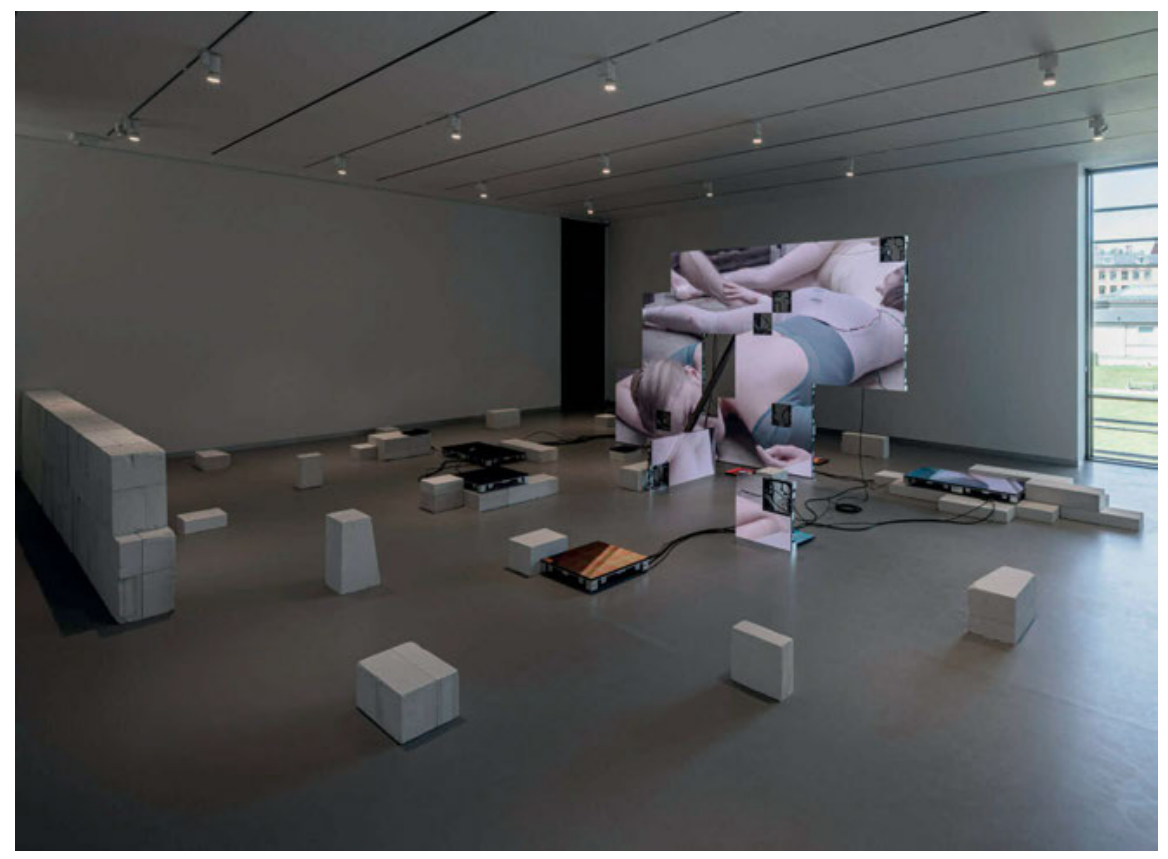

Figure 14: Installation of Jesper Just's Circuits (Interpassivities), 2018, at the National Gallery of Denmark. Image Credit: Anders Sune Berg / National Gallery of Denmark 
performs the interpretative process from sound to movement. Circuits might be interpreted here as a form of touch: this is a work about points of connection, about touching and being touched by bodies, technologies, and music. In Circuits (Interpassivities), touch is a highly mediated process. There is the electronic patch touching the dancer's skin, which materializes into movement when electronic impulses run through the wires; but there are also bodies touching one another, a hand holding another hand or a foot, bodies spilling over into other bodies. The dancers' faces reveal no emotion; their stares are blank, turned inward.

In his work, Just often challenges conventional notions of the body, working with "perfect," disabled, aging, and transgendered bodies, and questioning and challenging normative expectations and ableism..$^{98}$ In Circuits (Interpassivities), individual bodies merge and form a collective order on which a microscopic lens zooms in: we see the texture of skin and fabric in extreme close-up, making tangible the parallels between textiles and pixels. The object of the film is not the individual being moved or touched, but a collective. Yet for the visitor, the emotional imprint of the artwork is very present. Indeed, the artwork operates with a multiplicity of things and objects that touch and move one another: bodies, bodies and technology, technology and architecture, artwork and spectator. The twelve-minute film is shown on a loop, on a fragmented large-scale screen situated in the middle of the room. The screen is supported by aerated concrete blocks and an iron beam. Parts of the screen are missing, and the cutout pieces are placed around the floor, standing or lying while still displaying the film. The impression is that of a puzzle that needs to be put together in order to show the screen as a seamless entity, but it is unclear whether we are in the middle of a construction or demolition process. Is the screen being assembled or taken apart? This sensation is emphasized by the white aerated concrete blocks distributed around the room, sometimes stacked into small walls, sometimes single blocks that enter into dialogue with the walls of the white exhibition space, making us aware that the room is also made up of building blocks. The visitor has to move through the exhibition space in order to see all the screens, and in the process becomes a moving part of the exhibition.

In an interview about Corporéalités, a 2020 installation with a similar setup made with dancers from American Ballet Theatre, Just compares the layout of his installation to an English garden, stating that he is occupied with the spectator's movement and the obstruction of that movement, and with how narrative is created by movement. ${ }^{99}$ As an experience predicated on movement and bodily sensation, Circuits (Interpassivities) gives the impression of a maze that is being 


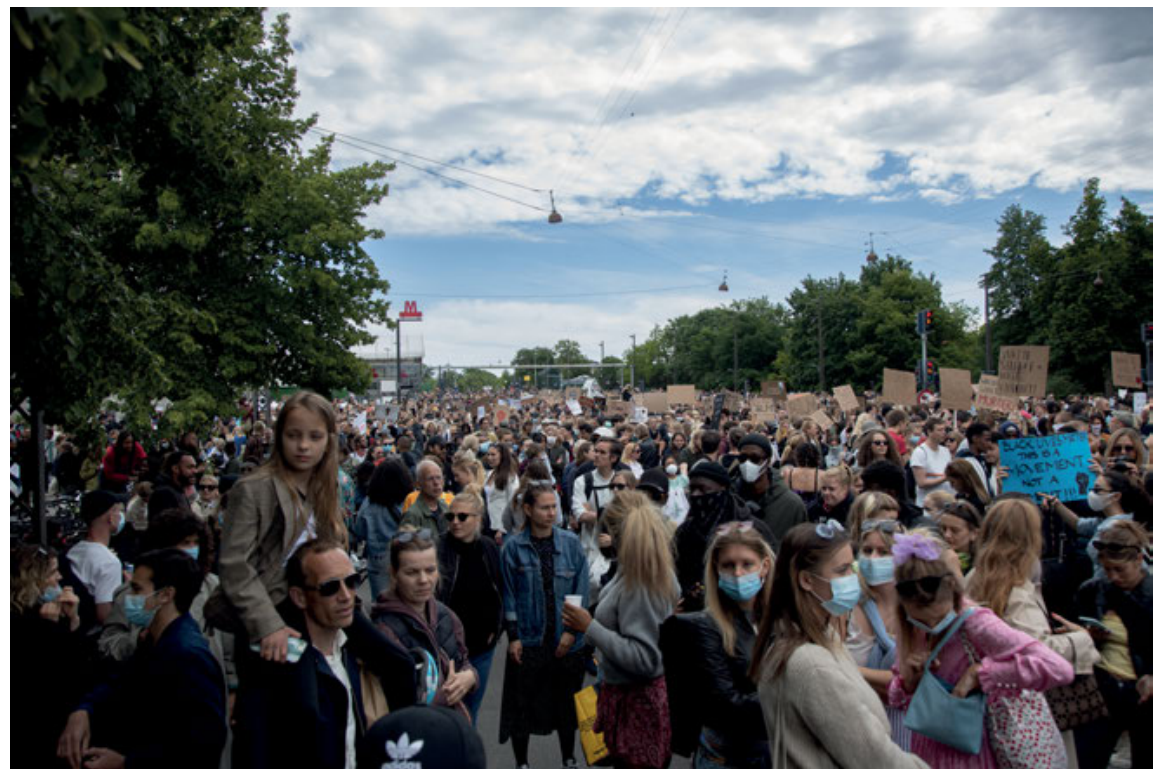

Figure 15: Copenhagen, Denmark, June 7, 2020: A Black Lives Matter demonstration with over fifteen thousand attendees, an expression of solidarity with the social and political movement in the US. Image Credit: Thomas Hollaender / Shutterstock.com 
built and mediated simultaneously. Is it a giant Pacman game where someone first ate bits of the screen and then spat them out onto the floor? Or are we inside a gigantic pixelated environment, where we are waiting for the gaps in the screen to load?

When the National Gallery reopened after the first lockdown, in June 2020, the experience of Just's artwork had changed significantly. Movement and its obstruction had taken on markedly different connotations during the couple of months that the museum had been closed. Like other arts institutions, the gallery had created routes and maps on the floor to guide visitors according to the rules of social distancing. The effect was not unlike the spatial choreographies with which Just works. When leaving the museum through the foyer, following the sticky labels on the floor, and emerging outside the gallery - perhaps with a phone in one's pocket registering close contacts in a contact tracing app - the sensation of being part of a collective of connected bodies whose limbs move and jerk would linger as one would make one's way toward the train station and put on one's mask before walking down the stairs.

American writer and activist Barbara Ehrenreich's 2006 book Dancing in the Streets: A History of Collective Joy outlines the history of festivities, public celebrations, and processions in European urban spaces, such as the medieval carnivalesque tradition. For Ehrenreich, these events are moments when physical togetherness in the city's open spaces entails a particular promise of collective energy. ${ }^{100}$ Although she sees this promise as largely forgone in contemporary society, an optimistic Deweyan interpretation would recognize here a certain possibility of public spaces: the possibility that bringing groups of people together around shared concerns might spark a public into being. ${ }^{101}$ Notably, Ehrenreich describes this productive way of coming together - in protests, for example - as a dance, a form of joy.

During the pandemic, we have seen a number of demonstrations in urban areas - in some cases peaceful, but in other cases violently contested by public authorities, as in Portland and other US cities. These practices are interpreted in a particular light in the context of lockdowns and limitations on how many people can legally gather, which have been imposed by many governments around the world. Despite the contradictory emotions it unleashed, for example, no one can underestimate the powerful imagery of the fifteen thousand people who, by walking the streets on June 7,2020 , were able for the first time to put 


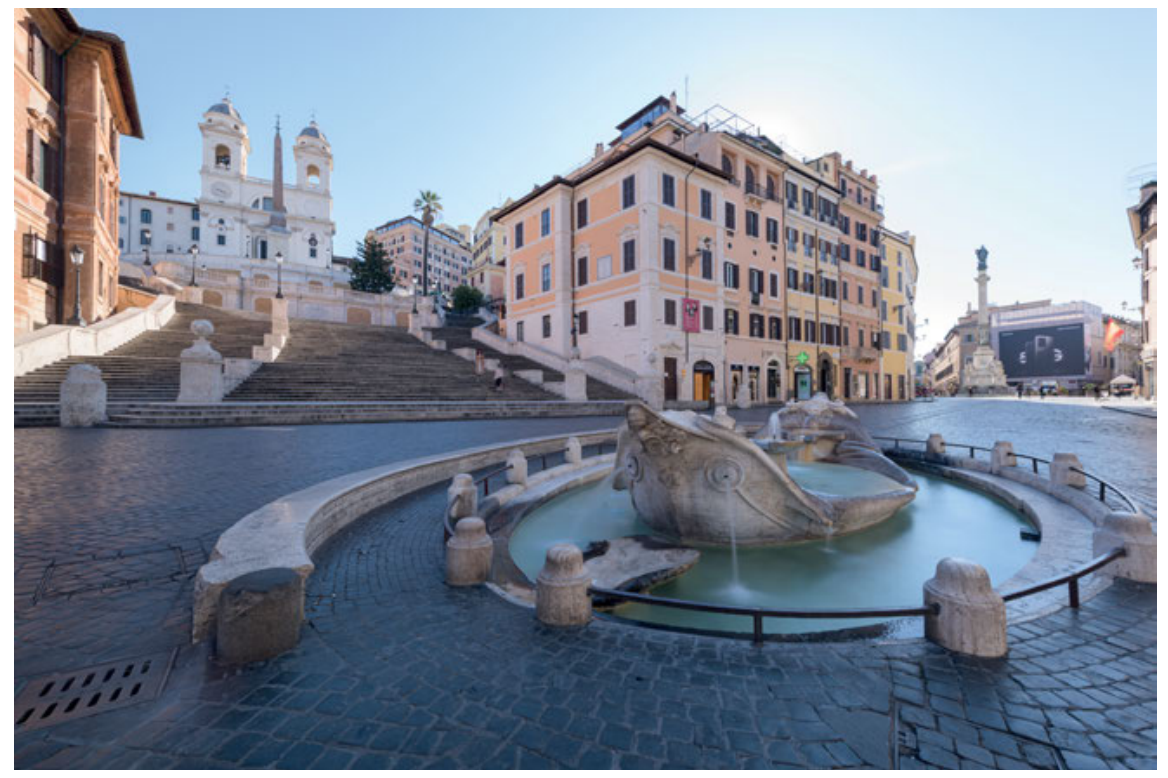

Figure 16: Across the world, even popular urban and tourist sites - such as the Spanish Steps in Rome, which are usually teeming with activity - were deserted for long periods during the first year of the COVID-19 pandemic. Image Credit: Em Campos / Shutterstock.com 
the idea that Black lives matter on Denmark's broad public agenda. It was powerful not least because at that time, although the lockdown was easing, many institutions were still shut, movement was restricted, national borders were closed, and basic rights were curtailed. If nothing else, the demonstration confirmed that movement was still part of the human repertoire of ways to inhabit, use, and go collectively in a kind of dance through urban public space. This coordinated and choreographed movement provoked a range of feelings that vacillated between fear, anger, moral outrage, encouragement, and joy. In late capitalist consumerist-oriented cities, where urban spaces are generally laid out for the spending of money on food, clothes, and other items as well as "experiences," urban protests and the political occupation of public space (by both the left and the right) have long been the subjects of scholarly attention..$^{102}$ In times of confinement, when the gathering of people is widely prohibited even in outdoor areas because of the fear of rapid viral transmission, urban protests prompt a series of complicated questions about what happens to our understanding of the individual and particular collectives when we are simultaneously more separated from and more closely tied to others.

As for urban centers, many consumers' spending patterns changed during the pandemic: much of the shopping and experience economy that used to take place in urban spaces or shopping malls moved behind digital screens, where browsing was free of the risk of contamination. But organized protests have seemingly found no such satisfactory outlets online. Moreover, as governments focus on reestablishing economic production and consumerist spending patterns from before the pandemic, we might wonder what that reestablishment will look like. Will the physical architectures of shopping soon become relics of a consumerist past? In the 1930s, the German-Jewish writer Walter Benjamin dedicated much of his work to grasping the arcades of nineteenth-century Paris as the ruins of modernity. ${ }^{103}$ Today, shopping malls, high street stores, and boutiques are different kinds of relics insofar as they are constant reminders of human frailty - of the potentially deadly touch of people circulating in the same spaces, touching the same objects, breathing the same air. When countries such as Germany and the UK closed stores in the weeks leading up to Christmas 2020, it was a huge blow to normalcy in a month that normally witnesses a surge in shopping. So, what will happen once the pandemic has subsided? Will people rush to shopping centers, high streets, and boutique areas to buy the things 


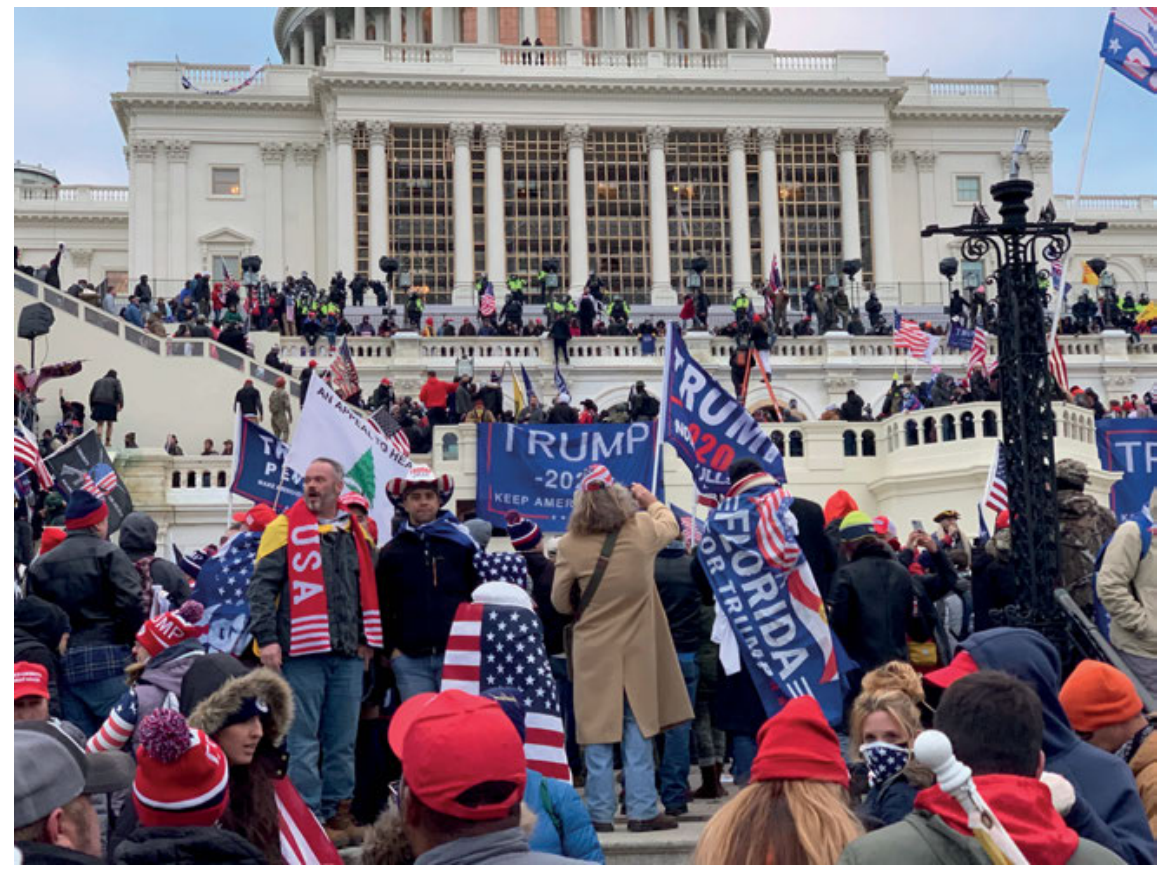

Figure 17: During the first year of COVID-19, restrictions were imposed in many parts of the world on gatherings in public spaces. This problematization of political protest saw peaceful and legal demonstrations interspersed with riots. An example that received global attention occurred in Washington, DC on January 6, 2021, during the last weeks of Donald Trump's presidency. Capitol Hill was stormed by rioters, including many supporters of Trump, who had held a rally nearby that morning. Image Credit: Sebastian Portillo / Shutterstock.com 
they missed out on buying, releasing energy by spending money? Or will we have endless miles of neatly organized shopping districts, empty of business but readily available for political protests, street fights, or collective forms of dance?

The rate at which individuals actually change their behavior to maintain distancing in public spaces during the pandemic hinges on both direct institutional power and the concrete articulations and readjustments of structures in the cities and communities around us. This means that this discussion cannot simply be pitched at intersections such as freedom vs. repression, rules vs. resistance, etc. Rather, we need to inquire into the components that choreograph the forms of dancing in the streets that are possible in the time of corona, and how this choreography hinges on complex power relations and particular conceptions of the individual. In her 1986 book How Institutions Think, anthropologist Mary Douglas states: "The pages that follow will not concern anyone who holds that the social order springs spontaneously into being." ${ }^{104}$ We will now take up some of Douglas's notions about the extra-individual power that is delegated to institutions, and we will intersperse those notions with Ehrenreich's ideas regarding how that power morphs seamlessly between constructive and destructive solidarity. This will set the scene for our subsequent reflections that dancing in the city streets in the time of corona may be partly joyful, social, and gracious, but partly also anxious, destructive, and exclusionary.

\footnotetext{
The conditions for stable conventions to arise are much more stringent than it might seem. Communities do not grow up into little institutions and these do not grow into big ones by any continuous process. For a convention to turn into a legitimate social institution it needs a parallel cognitive convention to sustain it [...]. A convention is institutionalized when, in reply to a question, "Why do you do it like this?" although the first answer may be framed in terms of mutual convenience, in response to further questioning the final answer refers to the way the planets are fixed in the sky and the way that plants and humans or animals naturally behave. ${ }^{105}$
}

“Why do you do it like this?" It is a question that we usually forget to ask ourselves or others. Most of what we do is part of the everyday commonplace constituted by background and routine actions, requiring no questions to be asked. But sometimes one is jolted out of the ordinary, and the question "why do you do it like this?" rings with a different tone. Imagine a scenario where you are returning to your home city after having been away since before the pandemic arrived, with no knowledge of what has unfolded in the meantime. Perhaps you 


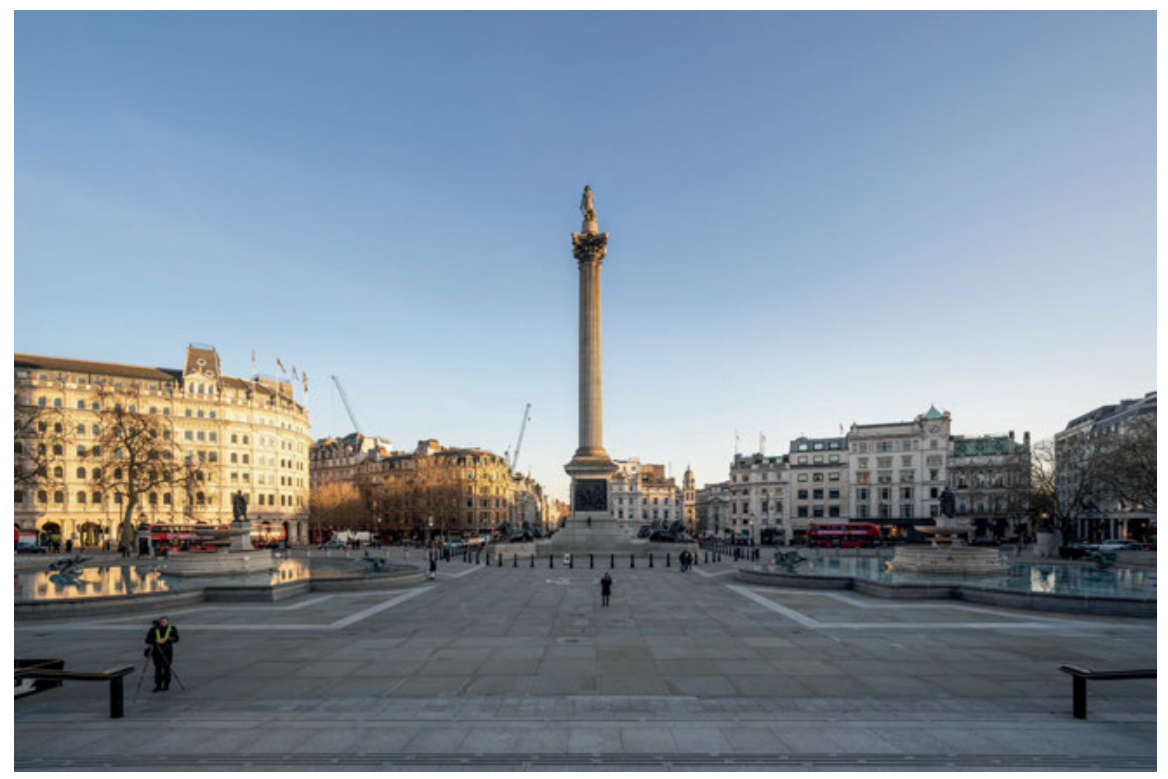

Figure 18: In the British postapocalyptic horror film 28 Days Later, directed by Danny Boyle, the protagonist wakes up to find London deserted due to a highly contagious virus outbreak that turns people into ravaging zombies. In March 2020, during the UK's first COVID-19 lockdown, Londoners also experienced empty streets and squares in the city, such as the usually bustling Trafalgar Square, due to a contagious virus, albeit without zombies. Image Credit: Sebastian Portillo / Shutterstock.com 
were trekking in the mountains, or living in an isolated community for a couple of months. Or imagine a situation where you have been shipwrecked on a desert island, like Robinson Crusoe in Daniel Defoe's 1719 novel, or Tom Hanks's character in the 2000 Hollywood movie Cast Away. Or even imagine returning from a place like Greenland, which registered a total of thirty positive cases between the start of the pandemic in March 2020 and March 1, 2021. ${ }^{106}$ On top of that, imagine that you had no access to (or deliberately avoided) the news during your time away, and so knew nothing about the pandemic. Now imagine that you are on your way home late at night, walking through your community to reach the place where you live. The streets appear strangely empty. You note that the bar down the road seems to have closed early. A travel agent has boarded up its shop windows, and the florist has posted a hand-decorated, heartshaped card stating that "we can't wait to have you back." You smile. Well, at least you are back now. You notice a homeless person wearing a face mask, and a surprisingly large proportion of dark windows in the high-rise hotel you can see on the horizon. But none of these observations trouble you. You look forward to finally sleeping in your own bed again. Indeed, now that the bar is closed, you have no problem falling asleep in the unusual silence of the neighborhood.

The next morning, you wake up refreshed, only to step out into the same quaint silence. As you walk to the nearest bakery, people seem to be avoiding you: they turn their heads and look the other way. At the bakery, people wait outside in a neatly spaced line. No one is talking to anyone. As you progress in the queue, you see that those ahead of you are either already wearing a face mask or put one on before they enter the store. You tap the shoulder of the woman in front of you, and you feel her shiver. She takes a big step sideways and says, "What's up?" in a brisk voice, adjusting her face mask so that it fits more tightly. "Why do you do it like this?" you ask. She looks at you blankly, making you feel that you are the odd one out. Is it your tan? Your smile? The colorful jacket you are wearing? "Just wear a mask, and please keep your distance," she answers. Inside the bakery, you see a newspaper bearing a headline about the pandemic death toll. Now it is your turn to shiver. The woman working in the bakery stands behind a plastic screen. A big sign tells you to wear a mask in the store, limits the number of people allowed in the room, and asks everyone to keep one meter apart from each other while they are being served. You mumble something about being sorry for not having a face mask but can you please have some bread, and the woman quickly hands you a disposable surgical mask. You put on the face mask and pay, lightly touching the plastic glove on the hand that passes you the wrapped bread, before you rush home. 
Of course, if this were a true or even realistic story, our protagonist - "you" - would have had a hard time finding anywhere on the planet without news of the pandemic, or indeed without the virus itself. Even in a scenario where "you" would have been outside of the information flow for months - like the protagonist in the 2002 horror movie 28 Days Later, who wakes up from a coma to find his hospital empty and central London deserted apart from the bloodthirsty zombies roaming the streets - it seems unlikely that you would be able to make it all the way home without seeing news about the pandemic on a phone or some other screen. ${ }^{107}$ Of course, the world is seldom quite as dystopian as a novel or a zombie movie, although the pandemic sometimes comes close and makes the question "why do you do it like this?" insistently relevant.

During the pandemic, particularly in cities where people live close to each other, daily life has been changed by a number of spatial means and practices introduced to combat rising infection numbers. Examples include the ways people avoid physical proximity, stay at home, reduce their social contacts, steer clear of confined spaces, wear masks, use hand sanitizer or frequently wash their hands, and sneeze into their elbows or handkerchiefs. All of these means are mundane and self-evident responses to what Douglas calls "mutual convenience." 108 They offer answers to the question "why do you do it like this?" when it comes to the practices of social life in the pandemic. If the answer is "just wear a mask, and please keep your distance," then the question "why do you do it like this?" seems trivial to the point of ridiculous. Yet it speaks to the changed everyday practices that people have internalized - whether through coercion, nudges, pleas, pointing fingers, or out of anxiety, self-preservation, care, trust, disbelief, or fear of standing out. Whatever people's motivations, these practices constitute a pandemic form of Douglas's "mutual convenience." That is, they hint at a form of solidarity and tap into issues about the formation of social bonds. This means that we must be on the alert when analogies, metaphors, and symbolic language are used to rationalize and legitimize the politics of choice as we are asked to change our behavior by limiting physical encounters, personal relationships, and the places, architectures, things, and animals with which we convene.

Notably, the call for distancing and restrictions in our relationships with other people, including in urban public spaces, means that people's appearance or sheer presence takes on a different meaning during the pandemic. In some situations, everyone around us appears to be dehumanized: other- 
worldly creatures, anonymized because their faces are covered, moving in ways that seem edgy and anxious, like scared animals, avoiding contact. The scenario is closer to a gothic mystery than to anything one would embrace rationally: humans are perceived as possible carriers of disease before they are perceived as individuals with affective relations to others. Limitations have been placed on the size of parties, groups, and social and work-related contacts. Children play with selected friends only. Older people or those with underlying health conditions sometimes completely self-isolate. Hugs, kisses, lovemaking, handshakes, or cuddles outside established monogamous relationships are suddenly problematized. The distance induced by the fear of others makes the societal body appear like a cohort of zombies.

The immense speed and wide-reaching effects with which political, societal, and behavioral structures were implemented is precisely what makes our story of the traveler's shocked return home both probable and improbable at the same time. Yet it also intuitively illustrates Douglas's point that institutions do not emerge through a continuous process. The COVID-19 pandemic's effect on daily life is not so much "the shock of the new" - a well-known trope in modern culture - but the shock of the revelation of societal and individual vulnerability. If we think back to how we felt and behaved in January 2020, many of us will probably acknowledge that we would then have given very different answers to the question "why do you do it like this?" than we would give today with regard to our behavior and bodily composure in public space. Indeed, for the "you" in our improbable story, the narrative could have developed very differently, as a romcom version of Robinson Crusoe rather than a zombie movie: the tanned traveler returns to their community, strong, wealthy, and capable of rationally fending off even the most gothic of creatures, and falls in love with the accidentally equally gorgeous person standing next in line in the bakery queue. In pandemic times a meet-cute in real life is fraught with a host of different emotions: physical proximity may cause an anxious shiver rather than a heart rate accelerated by flirtation.

If "dancing with corona" is anxious and unjoyful - a dance about maintaining distance and avoiding intimacy with viral pathogens represented as wild and dangerous beasts - it is not just metaphorical. As we adopt changing patterns of bodily movement, posture, and behavior in and around other people and public architectures, urban and institutional life is choreographed anew. While these 


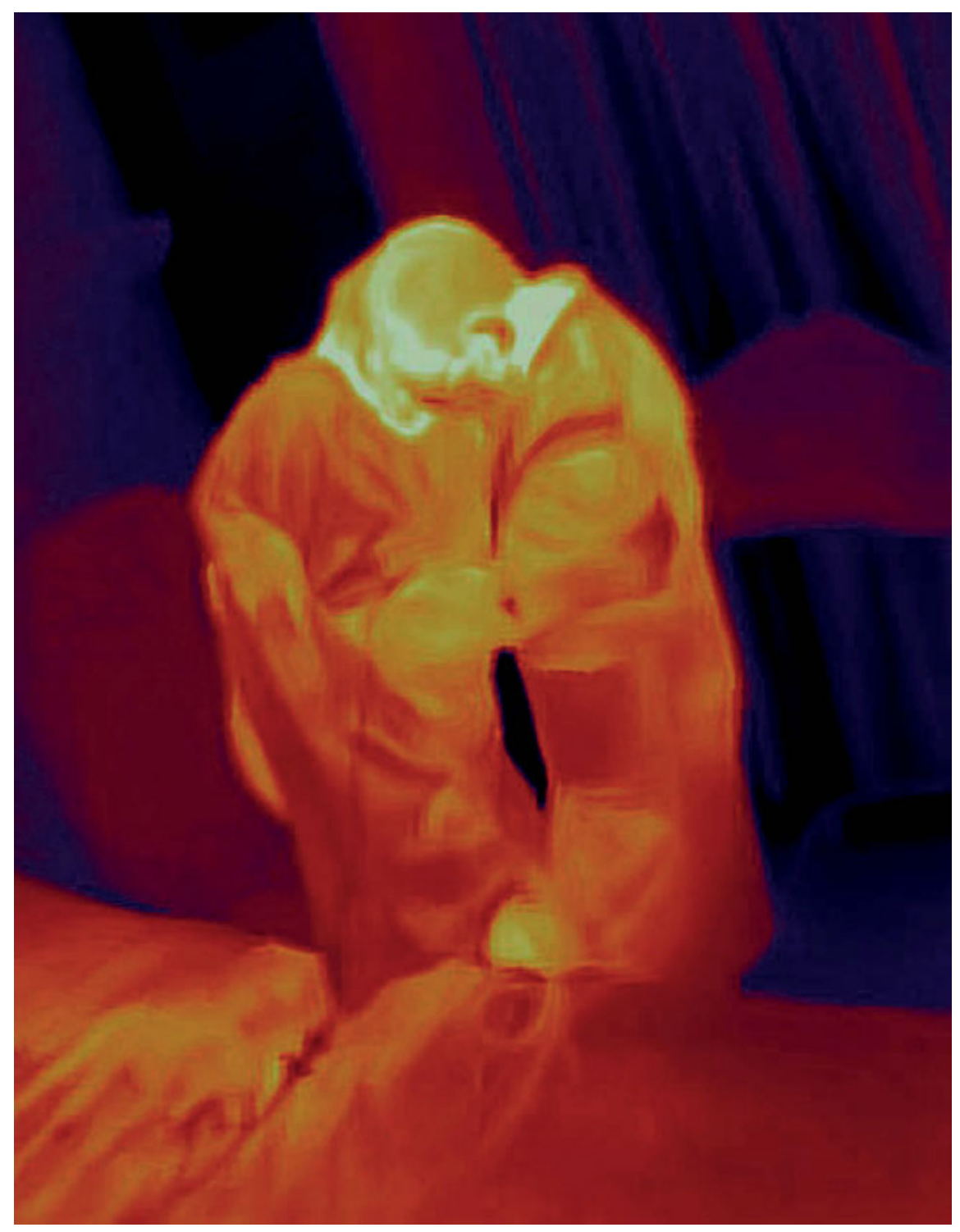

Figure 19: Antoine d'Agata's thermographic images document the streets and intensive care units of France during the pandemic. The images from the pandemic are evocative in their portrayal of human vulnerability. In these photos, humans touching each other become a layering of warm shades of orange, evoking the sensation of touch as a warm imprint on the skin of the audience. We are reminded of the lyrics of Leonard Cohen "Dance me through the panic till I'm gathered safely in/ Touch me with your naked hand or touch me with your glove/ Dance me to the end of love." Image Credit: @ Antoine d'Agata / Ritzau Scanpix 
movements take hold of our bodies in new ways, and distance becomes ingrained in how we touch each other in the time of corona, we would like to highlight that this mode of dancing is a form of collectively choreographed movement. It is driven not only by fear of contamination, but also by feelings of solidarity, shared compassion, and concern. This is so not least because the effects of not following the pandemic's choreographic rules can be devastating, both for us as individuals and for the people around us. Yet, following Ehrenreich, this form of dance plays out along difficult fault lines where solidarity meets competitive betrayal: in the greater socioeconomic and political reconfigurations brought on by the human response to the pandemic, some people will win, and some will lose - lose their livelihoods, or even their lives. Thus, solidarity can manifest both constructively and destructively, and we can see how ways of conforming to the politics of the pandemic can involve the kind of constructive solidarity expressed in social justice movements, as well as the forms of destructive solidarity expressed through war actions. ${ }^{109}$

It is evident that there is deep and divisive confusion about whose battle we are fighting when adjustments to bodily and cultural customs are linked to ways of "fighting" corona. For example, one kind of solidarity and embodiment of the greater societal good - occasionally described in specific terms as pertaining to the health care system - is sometimes positioned over and above all others. ${ }^{110}$ We are not contesting the absolute significance of a functioning medical system - either for society in general, or for individuals requiring treatment for COVID19 or other diseases during the pandemic - but we recognize that this focus prompts a host of difficult questions about the complicated, differentiated costs of particular political prioritizations and their wider effects on political choices and institutional restructuring during the pandemic. What we can do here is to raise questions about what happens to basic categories - such as public goods and the social bond - and how those categories are affected by changes to public architecture and behavioral norms. Moreover, we can try to trace how the human and political response to the pandemic grinds its way through understandings of what knits together and alters societal institutions, allowing new metaphors, morals, and ethics of togetherness, individuality, and the societal body to emerge and take hold. Some of these concepts entail huge costs in terms of individual rights, and the massive spending of public funds to fight a single battle. But some might also evoke deeply meaningful responses that have to do with care, carefulness, and positive, constructive solidarity in the face of human frailty, and have the potential to become ingrained in new ways in the bodies and minds of people living through this pandemic - thereby perhaps sparking 


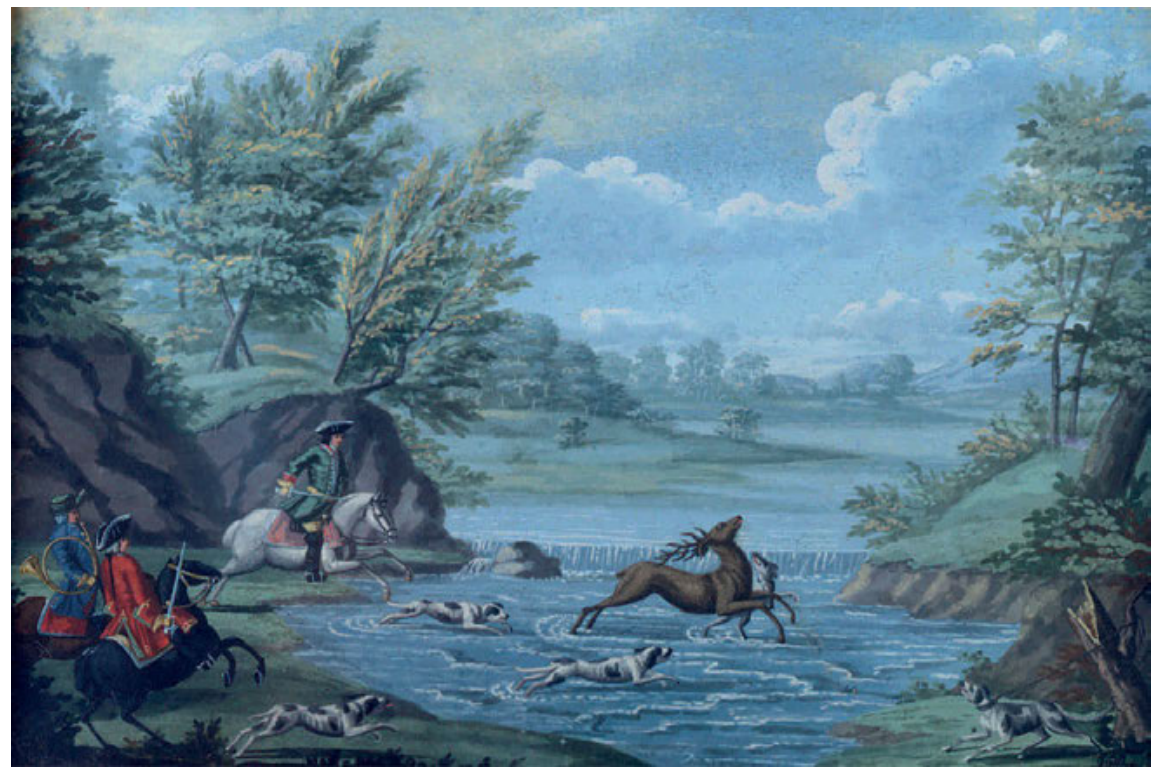

Figure 20: In hunting par force, a deer or wild boar was chased down until the dogs could get hold of it and the king, or a guest of honor, could ride in front and perform the killing. This eighteenth-century image is from the vast par force landscape north of Copenhagen, Denmark. Image Credit: Parforcejagt i Nordsjælland, Johan Jacob Bruun, circa 1750 / Det Grønne Museum 
more just and less individual-centered forms of coexistence that take into account a wide range of feelings and vulnerabilities.

In her book about cancer, Boyer writes: "The system of medicine is, for the sick, a visible scene of action, but beyond it and behind it and beneath it are all the other systems, family race work culture gender money education, and beyond those is a system that appears to include all the other systems, the system so total and overwhelming that we often mistake for the world." 19 pandemic, we may rewrite this statement as follows: the urban politics of the pandemic is, for anyone living in pandemic times, a visible scene of action, but beyond it and behind it and beneath it are all the other systems, family race work culture gender money education, and beyond those is a system that appears to include all the other systems, the system so total and overwhelming that we often mistake for the world.

The focus on health, the health system, political authority, and direct power during the pandemic always involves ethical principles, and it reflects particular morals that foreground some issues over others and have particular economic and social consequences. Despite the very real problems that arise from the COVID-19 pandemic, and which require prompt answers from politicians and administrators as well as from doctors and other health workers, these decisionmaking processes touch the core of how institutions work as extra-individual entities in the sense that Douglas proposes. In her effort to unravel how our ways of thinking, feeling, and acting are dependent upon institutions and their particular legitimizing structures, Douglas writes: "There needs to be an analogy by which the formal structure of a crucial set of social relations is found in the physical world, or in the supernatural world, or in eternity, anywhere, so long as it is not seen as a socially contrived arrangement."112

Dealing with COVID-19 has been described through the metaphors of the hammerblow and the dance. ${ }^{113}$ The hammering down of infection numbers through hard lockdown is followed by a period of interplay with the virus during which it is held sufficiently at bay to keep society functioning. The metaphor of the dance acknowledges this period of interplay as a process involving both partners - unlike the combative metaphors of fight or battle, or the view of the virus as something that came upon us humans from outside, like a storm. ${ }^{14}$ Another metaphor for the virus, reportedly used by Søren Brostrøm, the head of the Danish health authority, ${ }^{115}$ is the tiger. The act of taming a tiger, turning it from a wild beast to an innocent kitten, is not about putting the animal down. 
Instead, it conjures up the image of a species that humans will keep among them in an assimilated manner - indeed, with which humans will enter into a relationship that is like a dance. The metaphor of taming the tiger is thus akin to the metaphor of the dance: a dance with the tiger with which we can think Douglas's statement through. The virus as tiger evokes a wild exotic beast, but it is a beast that can be conquered and put down by the hunter, or tamed and put in a cage. But a tiger, after all, is not an unknown creature: there is a history of hunting, catching, and confining tigers in zoos and circuses, and tiger hunting is often associated with imperialism. ${ }^{116}$ By association, the image also calls on premodern notions, such as the Assyrian kings who hunted lions from chariots, or the medieval and baroque aristocracy who hunted par force - the noblest form of hunting. The hunt par force staged danger in a ritualized and controlled way, violently chasing the game for long stretches. At the end, the king, prince, or sovereign would step in and kill the animal in one glorious act - at which point the meat would taste so foul, because of the stress hormones released by the chase, that no one would care to eat it. ${ }^{117}$ But taming or dancing with a tiger is something different than hunting to kill. It suggests a level of interaction, an equality between two partners that acknowledge each other's presence and form choreographed patterns of movement. Nonetheless, the metaphor of the hammerblow of lockdown implies that the danger never quite subsides, because the virus remains latently present even when infection rates have been leveled by various measures. For a long time, it seemed that killing the virus with a vaccine would be a glorious ending, spearheaded (!) by scientists, pharmaceutical companies, and rich nation-states in the societies and economies we know in the West. But it is now increasingly acknowledged that even herd immunity brought about by inoculation will not kill the virus. Rather, the dance will continue in some form or other, even though the immediate pandemic danger of COVID-19 will subside. ${ }^{118}$

This story of the dance, and of dancing with or taming the tiger, is a story in which we are all required to participate in some way: we are all invited into some version of the dance with the tiger. Even those who subscribe to the conspiracy theory that the whole pandemic is a hoax to gain control of the population have to move according to the regulations in force. Indeed, dancing with corona in the shape of a tiger makes this dance appear normative. As a largescale institution in its own right, the constantly shifting and evolving political response to the COVID-19 pandemic works in ways that are closer to the institutions of a belief system - with quasi-sacred undertones that respond to latencies rather than absolutes - than to any accurate medical argument. As Italian philosopher and activist Franco "Bifo" Beradi aptly notes in the epigraph to this 
chapter, we can turn our attention instead to questions of use value, and to the tactical issue of how to create forms of collective knowledge that will envision ways out of the situation. Yet, as an institution, the regulations are able to do the thinking for us. If we get used to their pace, rhythm, flow, and steps, we will no longer need to worry so much about how to go about our daily lives; we will no longer need to ask the question "why do you do it like this?" - which may feel like being set free.

But this sensation only applies when the regulations are clear-cut and leave no room for interpretation, which is the case only under the strictest forms of lockdown. Instead, we are faced with a host of uncertainties and a constant need for interpretation, resulting in many different normative systems when mundane tasks suddenly present moral dilemmas. Do I go to a birthday party with fifty-one other people if the regulations limit gatherings to fifty? Do I go to a party with forty-nine people? Can my child attend soccer practice even if it significantly increases the number of people we engage with as a family? Should we gather ten people for Christmas if the regulations allow us to, even if we know that two or three of these people are elderly and vulnerable? Do administrative personnel at the university have to go into their offices in solidarity with the teaching staff, or should they express solidarity with a larger collective by working from home? Who gets to decide that one person is at greater risk than others and should be particularly protected at work or in public? Who are the most vulnerable or indispensable, and who should be first in the vaccination queue? Should I take the vaccine offered if it comes with rare but severe side effects? Such dilemmas multiply by the minute every time a new regulation is communicated.

Moreover, these dilemmas, and our own implication in them, may distract us from seeing that beneath it all lie the other systems - family race work culture gender money education - that influence how the pandemic is experienced and what consequences it has for individuals and communities. There is plenty of evidence to suggest that the effects of inequality pertaining to these measures strengthen the unequal risks and effects of the pandemic. ${ }^{119}$ That particular institutional structures produce new formations and tap into existing inequalities should come as no surprise. In other contexts, other analogies have been used to legitimize particular hierarchies or exploitative structures, often as when the pandemic takes the shape of a tiger - cutting a vast object or structure down to the scale of something tangible and close to the body. As Douglas writes: "In modern industrial society the analogical relation of head to hand was frequently used to justify the class structure, the inequalities of the educational system and the division of labor between manual and intellectual 
worker. The shared analogy is a device for legitimizing a set of fragile institutions." ${ }^{120}$ Perhaps we may think that the wilder the analogy to explain the relations between the mundane and the sacred, individual and shared freedom, etc., the more fragile the institution. If so, the idea of dancing with a tiger should raise all our red flags. 